OPEN ACCESS

Edited by: Sara Invitto,

University of Salento, Italy

Reviewed by:

Ines Testoni

University of Padua, Italy

Michael Alexander Wieser,

University of Klagenfurt, Austria

${ }^{*}$ Correspondence:

Aisha Sanober Chachar aisha.chachar@synapse.org.pk; aishachachar87@gmail.com

Specialty section:

This article was submitted to Public Mental Health,

a section of the journal

Frontiers in Psychiatry

Received: 16 January 2021

Accepted: 24 August 2021 Published: 29 September 2021

Citation:

Chachar AS, Younus $S$ and Ali W (2021) Developmental Understanding of Death and Grief Among Children

During COVID-19 Pandemic: Application of Bronfenbrenner's Bioecological Model.

Front. Psychiatry 12:654584. doi: 10.3389/fpsyt.2021.654584

\section{Developmental Understanding of Death and Grief Among Children During COVID-19 Pandemic: Application of Bronfenbrenner's Bioecological Model}

\author{
Aisha Sanober Chachar ${ }^{1 *}$, Sana Younus ${ }^{2}$ and Wamiq Ali $^{1}$ \\ ${ }^{1}$ Synapse, Pakistan Neuroscience Institute, Karachi, Pakistan, ${ }^{2}$ Menninger Department of Psychiatry and Behavioural \\ Sciences, Baylor College of Medicine, Houston, TX, United States
}

COVID-19 Pandemic has influenced death-related attitudes and understanding during the childhood development leading to a life-long impact. Factors like pandemic-related movement restrictions, school closures, and parents' stay-at-home have exposed children to the phenomenon of grief and death. In that case, children anticipate adverse outcomes and fear while they struggle with unanswered questions. Children may not have coping skills needed to manage their grief in constructive ways to identify, normalize, and express their responses to the loss in their lives. Naming and validating these responses as distinctive aspects of grief process and providing safe space to express their feelings are essential components of a child's coping with loss and grief. This is crucial to consider, as different children react to and are influenced by their environments differently. This article aims to explore the developmental understanding of the process of death and grief by applying the conceptual framework of Bronfenbrenner's theory. Understanding mutual interaction between a child and various ecological systems determines how children perceive death and process grief can facilitate effective communication that has significant implications.

Keywords: death anxiety, developmental perspective, Bronfenbrenner's ecological model, COVID-19 pandemic, child and adolescent mental health

\section{INTRODUCTION}

During the initial 14 months of the pandemic, more than 1.5 million children lost at least one primary caregiver (parent or grandparent) due to COVID-19-associated deaths (1). As the pandemic resulted in a substantial increase in deaths caused either directly by virus-related complications or indirectly due to limited access to health care services for chronic diseases and medical emergencies, the children's exposure to the phenomenon of death also increased exponentially (2). Children and adults differ in reacting to pandemics (3). Thus, children living through the pandemic can imbibe worries from various sources within their environment. Furthermore, these anxieties can influence each child differently depending on their developmental level of cognition and baseline understanding of death. The trauma of losing a parent or a caregiver can be a devastating life event for a child. These experiences are associated with increases in mental 
health conditions, substance use disorders, and chronic health conditions. To prevent further adverse consequences, the need for providing and ensuring access to evidence-based psychosocial support to these grieving children has become essential. It should not be neglected while responding to the pandemic. Thus, in assessing the grief process and children's understanding of death, it is essential to consider child's experiences, their interaction with adults, the broader culture, and exposure to losses. In addition, the child's developmental age, educational status, pre-existing mental health condition, economically underprivileged background, quarantined, and pandemics-related routine changes influence this process (4, 5). The present review uses Bronfenbrenner's bio-ecological model to discuss the contextual factors that shape the cognitive understanding and the psychological impact of death and grief process among children in the COVID-19 pandemic (Table 1).

\section{FACTORS AFFECTING CHILD'S UNDERSTANDING OF DEATH AND GRIEF PROCESS}

\section{Developmental Understanding of Death}

The innate cognitive ability of a child to understand the concept of death expands during the early stages of development. This does not mean that children do not understand the notion of death. Even though their understanding is limited, they still strive to make sense of loss and grief (6). Children's ability to comprehend death and grief depends on their developmental stage, life experiences, individual temperament, parental communication patterns, and support from their environment (7). Earlier perceptions about death evolve progressively with age. Speece and Brent (8) identified these concepts according to children's cognitive representation of death (Table 2). According to these theoretical concepts, for a 4 -year-old, death is reversible, which means if someone has died, they can come back to life. Children also do not fully conceptualize the fact that they are mortal. Instead, they believe death happens to older people and, in some instances, evil people. By the age of $8-10$, children now comprehend personified death as an unavoidable life event.

\section{Death-Related Emotional Responses}

Emotional responses to death include uncertainty, fear, and anxiety. These responses depend upon an individual's comprehension and appraisal for threat, meta-cognitive beliefs, intolerance of uncertainty, cognitive biases toward physical symptoms, and existential concerns, including death and dying (9). Uncertainty is an inability to determine and predict the meaning of ongoing events. It can be a result of ambiguity, i.e., conflicting, incomplete, or inadequate information; complexity, i.e., difficult to understand information; and unpredictability, i.e., likelihood or risk of the future outcome of the event (10). When faced with uncertainties, children and families might feel paralyzed and struggle with making urgent or everyday decisions (11). Fear is a powerful emotion that plays an essential role in survival and induces a fight or flight response. Regardless of one's response to fear, it thrives on unfamiliarity and lack of information. It can be spontaneous or deliberate (12). It can also invoke a response to anticipated threats or thoughts about potential dangers, generally manifested as anticipatory anxiety. These emotions in current times can arise due to existential threats, uncertainty about a disease process, available treatments and vaccinations, and loss of meaning and coherence. In some instances, anticipatory fear may precede an actual pandemic. Subsequently, these reasons impact one's behaviors, cognitions, emotions, and interpersonal skills.

\section{Fear of Death, Death Anxiety, and Death-Related Attitudes}

Fear of death is a conscious phenomenon specific to dying. Reasons to fear death include loss of self, fear of the unfamiliarity, pain, suffering, and leaving family members in distress (13). In contrast, death anxiety is considered to be unconscious and more generalized in nature. Death anxiety includes avoidance and acceptance. Death avoidance is an attitude toward death is when a person attempts to avoid thinking or talking about death. Note that death avoidance differs from fear of death which results from confrontation with death and the emotions attached to it (13). Whereas, death acceptance is the ending and desirable stage of coping with death itself (14). It is a psychological readiness for the final separation from life that consists of the cognitive awareness of mortality and a positive emotional reaction to that awareness $(13,15)$. Different attitudes represent death acceptance. The first is neutral acceptance, in which a person perceives and accepts death as an integral part of life. They are not afraid of death but, at the same time, do not welcome it. The second attitude is approach acceptance, in which a person perceives death as a passage to a better afterlife. This attitude is significantly associated with religiosity (16). The third attitude is escaping acceptance, where a person perceives death as an escape from the pain of life, thus, a desirable alternative to life.

The question arises if the fear of death exists in most children who have not developed a fully mature understanding of death. In some instances, fear of death increases in early adolescence (17). This perspective suggests that even when a child achieves a mature understanding of death, additional factors influence fear of death. Developing a mature concept of death could affect children's fear of death in two ways. Either it could provoke it, or it could reduce it; the latter leads to reduction in child's struggle with unanswered questions about their earlier conceptualization of death. It remains unclear if interventions targeted to reduce fear of death would benefit those children who have mastered all five subcomponents of the death concept as some fear remains, even after achieving a mature understanding of death (18). Further research to investigate which possible developmental scenario would prove beneficial has significant implications for clinical and educational practices.

\section{Terror Management Theory}

Terror management theory (TMT) proposes that death anxiety drives human behavior (19). TMT reasons that death reminders increase the potential for experiencing existential anxiety, and can increase mental health symptoms (20). Continuing the 
TABLE 1 | Factors affecting the process of death and grief among children in the COVID in each system of Bronfenbrenner's bio-ecological model.

\begin{tabular}{|c|c|c|c|c|c|}
\hline Microsystem & Mesosystem & Macrosystem & Exosystem & Chronosystem & $\begin{array}{l}\text { Individual } \\
\text { characteristics }\end{array}$ \\
\hline $\begin{array}{l}\text { - Home environment } \\
\text { - Parental anxiety } \\
\text { - Parental emotional } \\
\text { grief reaction } \\
\text { - Parental education }\end{array}$ & $\begin{array}{l}\text { - Peer conversation } \\
\text { - Teacher's } \\
\text { communication } \\
\text { - Patterns of } \\
\text { communication and } \\
\text { support } \\
\text { - Family values } \\
\text { - Parenting } \\
\text { praticesProtecting } \\
\text { the child }\end{array}$ & $\begin{array}{l}\text { - Unresponsible } \\
\text { journalism } \\
\text { - Cultural beliefs } \\
\text { - Conspiracy theories } \\
\text { - Funeral Practices }\end{array}$ & $\begin{array}{l}\text { - Isolation, contact } \\
\text { restrictions, } \\
\text { economic shutdown, } \\
\text { limited out-of-home } \\
\text { leisure time activities } \\
\text { - Limited access to } \\
\text { healthcare } \\
\text { income loss }\end{array}$ & $\begin{array}{l}\text { - COVID pandemic } \\
\text { - Travel ban } \\
\text { - Changing policies }\end{array}$ & $\begin{array}{l}\text { - Age, gender, } \\
\text { temperament, and } \\
\text { resilience } \\
\text { - Developmental } \\
\text { stage, i.e., } \\
\text { cognitive, physical, } \\
\text { psychological, social, } \\
\text { spiritual } \\
\text { - Death } \\
\text { experience, trauma }\end{array}$ \\
\hline
\end{tabular}

TABLE 2 | Developmental stages during childhood and cognitive representation of death.

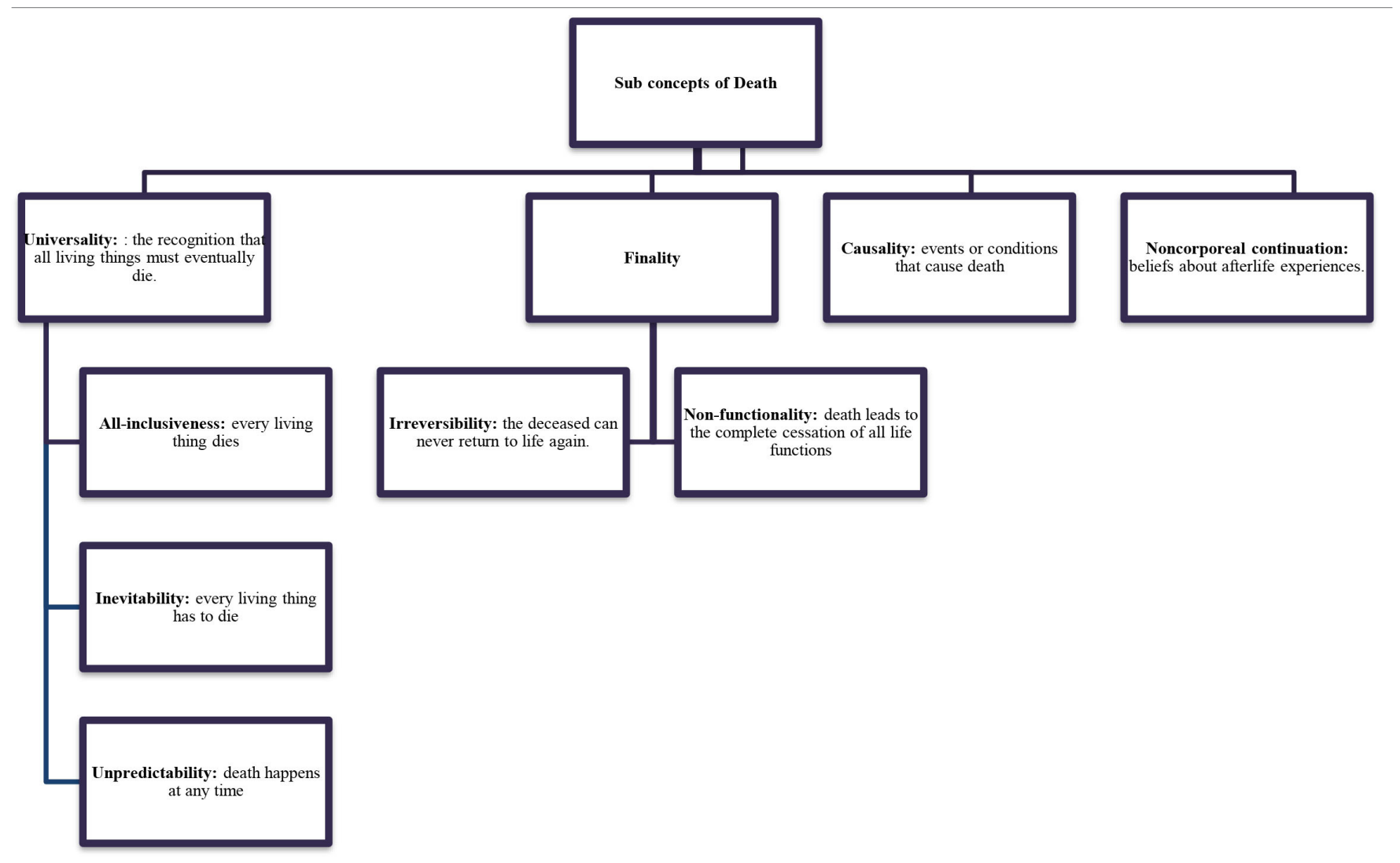

TMT principle, Morality Salience (MS) theory highlights the importance of innate belief systems to protect oneself from existential anxiety. Situations that demand confrontation to one's mortality, as evident in the current pandemic; there is an increased need to hold on to the existing belief system. Hence, any counter-narrative appears as a threat and any reinforcement of the current belief system provides psychological safety. During a threat to survival and prosperity, humans shift toward the collectivistic mindset (21). These theories suggest that the fear of death drives people to maintain their cultural beliefs at the expense of health related safety. Collective beliefs shared by the community can affect individuals' behavior or emotions when experiencing stress. This is termed "milling," described by Contagion theory (22). During milling, people become incredibly conscious of the crowd's attitudes and respond by adopting them to avoid external ridicule. Independent actions reduce through milling, and new behavioral patterns emerge from extreme collective behavior observed during the pandemic. These factors, directly and indirectly, aggravate the anxiety associated with the uncertain pandemic times for children and families. 


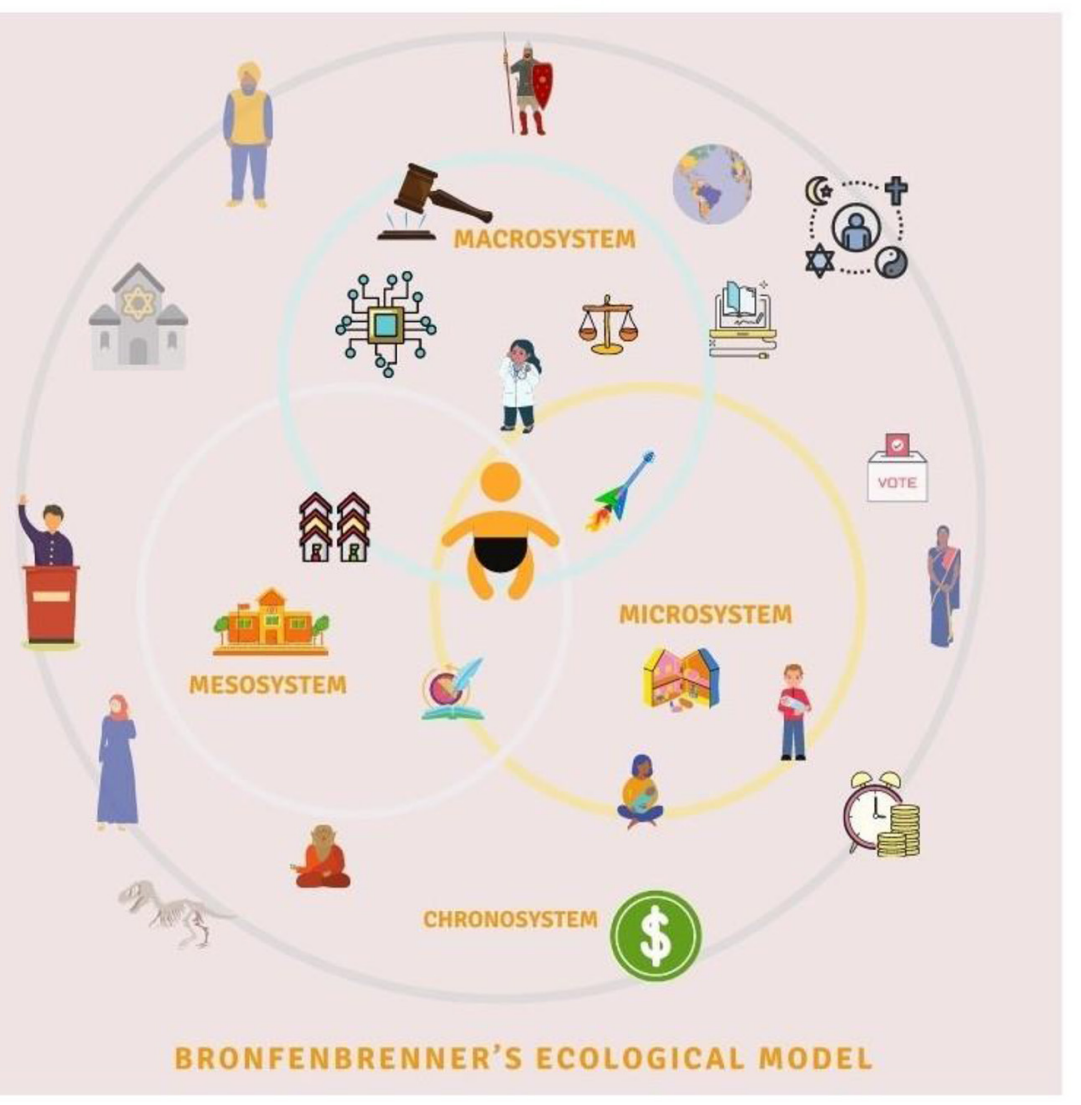

FIGURE 1 | Bronfenbrenner's bio-ecological systems and their interactions with childhood development.

\section{BRONFENBRENNER'S MODEL OF CHILD DEVELOPMENT DURING COVID-19}

Urie Bronfenbrenner's bio-ecological model provides a framework to describe how a child's innate qualities and environments influence growth and development in different settings (23). This model maintains the child at the central core with five encompassing systems, ranging from the most intimate to the broadest (Figure 1). These systems and their interactions with childhood development are crucial regardless of pandemic times. Nonetheless, the COVID-19 pandemic has further complicated the interactions between these systems at all levels (Figure 2). Thus, it is valuable to apply Bronfenbrenner's bio-ecological model to understand pandemic's impact on grief and death process among children.

The microsystem is children's immediate environment, including school, day-care, home, friends, and the local community or immediate neighborhood. The interactions between these constructs in the microsystem and the child's reaction toward them directly affect childhood development. The large magnitude of the COVID-19 pandemic has affected children in many ways. Although children appear to have lower mortality rates directly from COVID-19, the indirect impact has resulted in a rise in child mortality rates mainly due to the limited access to health services, immunization, and antenatal care; reversing decades of progress toward eliminating preventable child deaths globally $(2,24)$. On the other hand, the number of children losing a primary caregiver due to COVID-19 associated deaths is overwhelming (1). Subsequently, as the pandemic evolves, attempts are made to track the number of grieving children for each COVID-19 associated death (25). Sudden parental death secondary to COVID-19 can profoundly affect grieving children, putting them at elevated risk of traumatic grief, mood and anxiety disorders, poor educational outcomes, unintentional death or suicide, and consequences that can persist into adulthood (26).

Children who have not directly experienced the death of their loved ones have also been affected by the pandemic. Whether cohesive or disintegrated, the existing family system is compromised due to changes in routine and the introduction of online teaching. The risk of maltreatment, violence at home, and poor nutrition also increase for many vulnerable children. Children from disadvantaged backgrounds are more prone to being affected by the consequences of the COVID-19 outbreak. They are predisposed to poor health outcomes, lower physical activity levels, suboptimal diet, greater disengagement from school, lower academic performance, and more socio-emotional difficulties (27). Families' reactions to the pandemic-related 


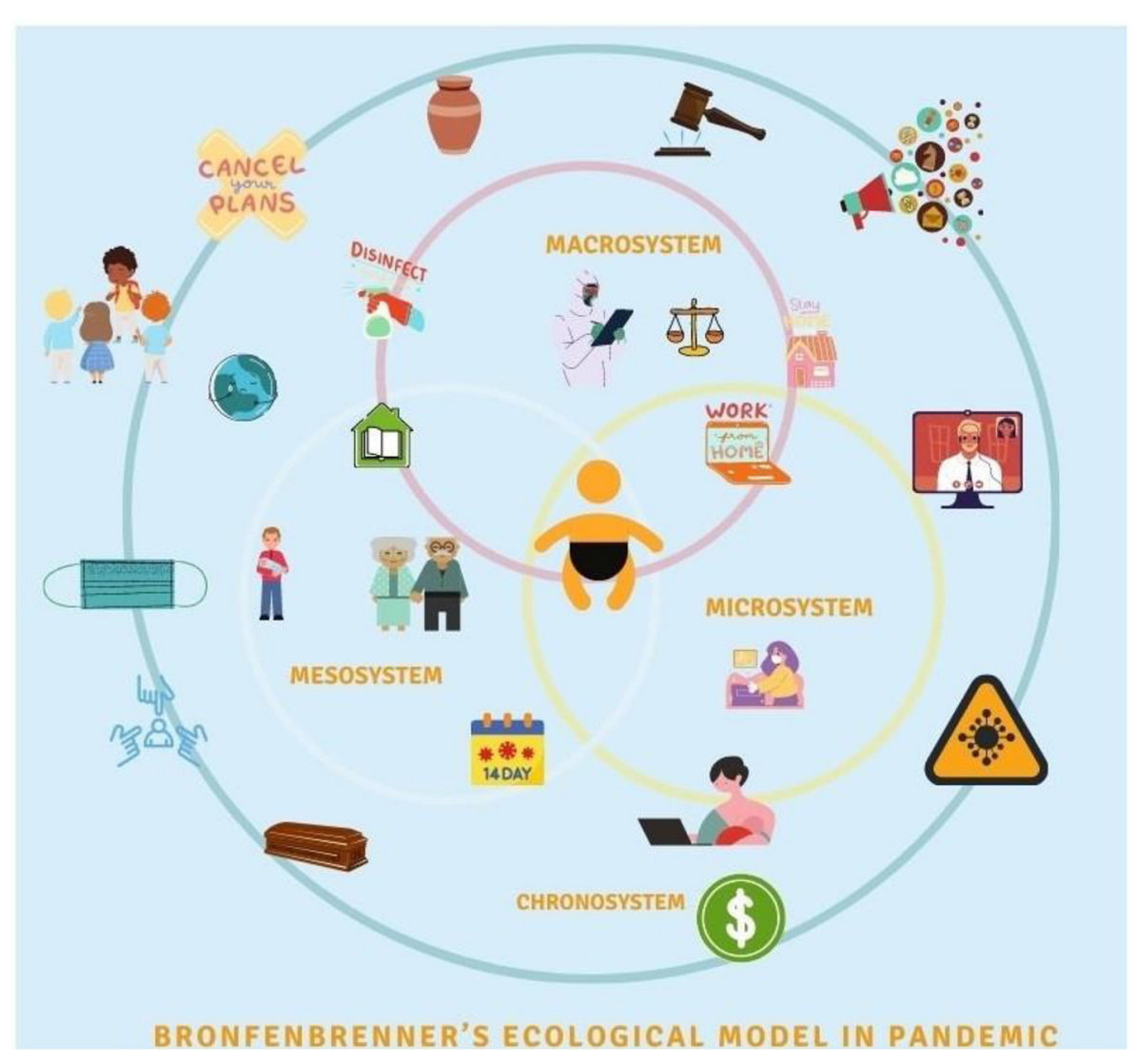

FIGURE 2 | Bronfenbrenner's bio-ecological model; systems and their interactions with childhood development during COVID-19 pandemic.

anxieties range from fear to indifference to fatalism $(3,28)$. Some families may disregard the risks and fail to engage in recommended health behaviors such as vaccination, hygiene practices, and social distancing. Others may react with intense anxiety or fear. Parents with anxious temperaments are likely to fear contagion and view the world as an existential threat, described in the literature as health anxiety and experience anxiety, respectively $(29,30)$. However, a moderate level of fear or anxiety encourages people to cope with health threats, but severe distress can be debilitating. This diversity of coping styles among families stems from their unique challenges. During the pandemic, the lack of support for parents from extended family members and other social support systems results in high levels of parental emotional distress (31).

The mesosystem includes the interaction of different microsystems. For example, it involves the connections between school and home, family and community, and between friends and family. During the pandemic, as children interact within various elements of their microsystem, information exchange during these interactions leads to an alteration of perception and attitude related to death. For instance, household conversations about vulnerability and risk associated with exposure for older family members, limited visitations to grandparents, health communications in schools, and outdoor activities can raise curiosity in children. This curiosity, if addressed, can lead to a better understanding of the situation. However, not addressing it can lead to confusion and invoke fear due to uncertainty. This multidimensional exchange multiplies the extent and impact of unanswered queries. There is uncertainty in the early stages of a pandemic, especially when outbreaks come in waves, with schools and workplaces closing for the while and reopening later in-person or in a hybrid fashion (32). As the curve flattens, a single incident of viral exposure disrupts the entire mesosystem. The cost of each exposure is multilayered. For a child exposed in school, one significant consequence is the cessation of in-person learning that is also emotional in nature. Blaming oneself as a source of illness, anger toward other children for not taking optimal precautions, and guilt associated with being responsible for the morbidity and mortality of someone else are some of the emotional reactions exhibited by children. On the other hand, parents worry about the risk of illness and associated fear of death compounded by stress associated with mobilization of resources for childcare as they manage in-person and online, work, and schooling (31).

The exosystem refers to the relationship between two or more settings that influences children's development. It includes available health services, employment opportunities, or neighborhood safety. Disruption in the exosystem during 
the pandemic adversely affects children as lockdown measures reduce opportunities for children to participate in extracurricular activities, which serves as a coping outlet for many children. Contact with supportive school staff, community members, and access to the justice system and child protection services are also decreased due to policies related to in-person gatherings (28). Children are also indirectly affected by elements of this system as their families are impacted by the economic shutdown leading to unmet basic needs (33).

The healthcare system is one of the most critical elements in this system that significantly impacts children's death-related attitudes. For an overall healthy child, pandemic disrupts annual physical exams, dental visits, eye exams, and routine vaccinations. In addition, emergent or urgent visits to the emergency rooms or clinics are associated with significant anxiety related to fear of exposure to virus during the visit. For children with comorbidities, routine hospital visits are associated with similar anxieties. However, these are magnified by new health care policies during visits, limitations associated with the number of adults accompanying children in health care settings, and contact precautions leading to limited access to resources like screens and toys. For children who require home healthcare services, nursing care is complicated by contact precautions and physical distancing. Despite common fear of shots, doctors' visits, and dental exams, health care settings are generally considered places where one gets help. During a pandemic, the fear of contamination associated with health care providers and health care settings can distort this image. This can be disorienting for children far from the developmental phase of identifying abstract and conflicting ideas.

Media is another crucial component of the exosystem. In the past, movies and TV shows have toned down death by immunizing the masses against its emotional relevance by exposing them to the frightening nature of pandemics in the context of entertainment (34). Nevertheless, to view a past pandemic in a movie is different from viewing live reporting of death tolls from one's lifetime; the latter is broadcasting one's reality which can have adverse outcomes. Moreover, daily exposures to death stats can cause emotional numbness in some, whereas it can trigger anxiety for many. This concern led to a media release by WHO declaring an "infodemic" crisis (35). Media has the potential to impact the development of children in positive ways. As the anxiety associated with health care settings rise in children and families, they also observe the collective effort of first responders and health care providers to provide care for those in need at the cost of their personal safety. On the one hand, as media portrays the deficiencies and incompetence of governmental organizations and highlights the daily surge in cases and deaths, it also showcases the strength of communities in these difficult times. These and many other examples of unity serve as tools used by caregivers to alleviate illness and deathrelated anxiety.

Macrosystem are "blueprints" for interlocking social forces and their interrelationships in shaping child development. It consists of culture, beliefs, ideas, and the political and economic system. They provide broad ideological and organizational patterns that are not static but might change throughout time due to economic, geopolitical, and technological changes. Children's perception of death-related attitudes are also formed by their cultural values and geographical location. For instance, death experiences for children in a war zone area is related to witnessing daily violence. Their death attitudes differs from those living in peace and prosperity (36). This has a relevance as majority of the children affected by COVID-19 associated deaths are from countries with ongoing political unrest, thus, complicating the grieving process (25).

The political and economic system plays a significant role during the pandemic. As the outbreak spreads globally, each country becomes a key player in its containment and management. As the global political struggles continue to control the spread of the virus, inequities in the allocation of health care funding worsen the economic burden in various countries. Closure of businesses, travel ban, limited financial support and allowances by governments, layoffs from jobs further added to this burden.

COVID-19 pandemic has high morbidity and mortality rate. As the death toll mounts, the compounded weight of pain and loss disrupts the ability to grieve, affecting cultures and faiths worldwide. Communities mourn alone with nationwide lockdowns while taking care of their sick (3). Each culture and religion has a different explanation and response to the pandemic that occurs with collective denial of impermanence and mortality in the background. The attitude toward precautions and treatment varies according to these cultural explanations. In many cultures, people seek help from ancestral spirits and trust their elders and traditional healers, seeing them as the custodians of culture who guide them regarding life's conduct (37). People tend to resort to their culturally prescribed religious practices to cope with the anxiety stemming from the existential threat of the pandemic. Social and physical distancing makes these difficult as most religious practices comprise congregational rituals and ceremonies. The inability to meet with trusted fellow community members and praying together to preserve the sense of cohesiveness during times of uncertainty is distressful especially on religious occasions. Easter, Eid, Thanksgiving, Halloween, Holi, Diwali, Hajj, Christmas, Passover, and Hanukkah are observed unconventionally while adults resort to innovative ways to maintain a sense of cohesiveness. Holidays are vital to create valuable experiences for children, as they benefit from these times by developing social skills, interacting with others, and sharing their values with peers belonging to other faiths and cultures. Unfortunately, the pandemic compromises these practices and their outcomes in different ways.

Pandemic-related conspiracy theories complicated the situation further. For instance, the "Chinese virus" narrative originated from the United States and quickly spread to the entire world. The geopolitical landscape perpetuated racial discrimination against Asians ranging from structural and political to professional and personal levels. This contributed to emotional challenges for children of Asian descent and their peers living across the world. These perceptions arise during uncertainty, especially if the circumstances are threatening and personally relevant (38). Belief in conspiracy theories happens to be a culturally universal phenomenon (39). Believing that it 
is a "man-made virus" with bioterrorist intent, and vaccination induced infertility were some of the conspiracy theories that were the highlights of the year 2020 .

Chronosystem includes the context and dimension of time, including both change and constancy in the children's physical and social environment such as family, neighborhood, country, culture, and historical time. It also includes intangible factors such as values, customs, and ideals.

Among many religions, a widely practiced ritual is washing the dead body with bare hands and spending time with the dead body. Burial practices like these are among the most significant modes of spreading the disease and hence highly discouraged during the pandemic (40). The community's inability to bury the dead according to cultural and religious practices due to shortages of coffins and insufficient funeral staff can result in unresolved grief with hindered death-related closure $(41,42)$. Managing a loved one's funeral is an emotional time for bereaving families, and abandonment of traditionally prescribed practices can be perceived as dehumanizing at this challenging time (43, 44). As families struggle through the process of grieving and closure, children are impacted by their prolonged and unresolved grief which can manifest as confusion about the death of the family members, questions about the cause and meaning of death, and anxiety associated with their death and the possible death of living caregivers (45-47).

\section{IMPLICATIONS}

The exposure to death of a loved one or a threat (perceived or actual) toward their safety can interfere with the child's cognitive understanding of death. Below are the critical implications for various stakeholders keeping the view of Bronfenbrenner's ecological model.

\section{Children's View of Pandemic}

Children fear parental safety more than personal safety in the current context. They face uncertainties about being infected, the seriousness of the infection, the optimal type of treatment or protective measures, and whether a pandemic is truly over. Children may also express concern about possible infection, a threat to family integrity, separation from their school friends, and, more importantly, about death. As a result, they manifest anger, restlessness, frustration, and disinterest (48). While adults are busy mitigating the risks and combating the crisis, the message to children translates as, "you are safe as long as you are indoors." Reassurance of this kind does not help the child's fear of parental safety. Instead, this account can also induce feelings of guilt related to being safe in the midst of a crisis. Many adults firmly believe that children are too young to suffer, understand, internalize, and remember traumatic events to which they are exposed. Therefore, they try to protect children from the emotional discomfort that death induces. There is a "general multi-determined tendency in too many adults to encourage children to deny and repress painful effects and threat-perceived real events, often to the child's detriment" (49). The need to mourn effectively and sufficiently is as much a right of children as that of adults. However, this need must match the child's developmental ability and tendency to regulate emotions with parental emotional availability (50). Resilience allows adaptation in the face of adversity and trauma while enduring the pain and distress (51). Practicing strategies like cultivating a positive self-image, maintaining hope, and keeping things in perspective can nurture resilience (52). Children respond well to reassurance and accurate and timely information about the environment's isolation status and expected changes. Empowering children in quarantine and isolation by including them in the decisionmaking process helps restore dignity and a sense of self-worth in challenging situations (53).

\section{Child's Grief Reactions}

Acute grief reactions vary with symptoms unique to the loss experienced, which can be painful and impairing but do not necessarily represent a mental illness (54). Unfortunately, these reactions are not fully understood due to a lack of recognizing secondary stressors integral to the bereavement experience (55). The child not only deals with the loss of the deceased person but also worries about adjustments concerning various aspects of life; adaptation to loss involves restoring coherence to the narrative of the child's life (56).

For adults, grief is typically an unusual and disturbing experience. It is more so for children who may have even less understanding of what is happening or can happen to them. The child's cognitive and emotional development influences these reactions. For some children, grief comes in relatively short bursts over an extended time. This uneven or intermittent course of suffering is one of the most exclusive and typical childhood bereavement features. Some children may experience more intense grief responses. Preschool children, may exhibit clinging and dependent behaviors, phobic reactions, sleep and appetite disturbances, nightmares, loss of bladder and bowel control, temper tantrums, and hyperactivity (57). The younger school-age children may not express psychological suffering but manifest it through play and behavioral symptoms. They often have sleep, appetite, and concentration disturbances, somatic complaints, irritability, hyperactivity, decline in school performance, and sibling rivalry. Older children can express unpleasant internal emotional states verbally. These include anxiety, panic, dysphoria, maladaptive behaviors, such as aggression and interpersonal conflicts. The adolescents may present with depressed mood, social withdrawal, suicidal ideation and behavior, defiance, impulsive behavior, and substance use (57).

\section{Communication}

Bereaved children and family members may also experience intense survivor's guilt. Support from a trusted spiritual leader, a therapist, or grief support groups play a therapeutic role and enhance a sense of social connectedness (58). Storybooks are a helpful tool to acquaint children with communication about death and grief (59). Feraco et al. (60) proposed four main approaches for caregivers: Acknowledge, Discuss, Do, and Reflect. A discussion of this kind with the child often helps them express some of their concerns and promotes trust, 
understanding, and control over the situation. Key aspects to consider while communicating with children are as follows:

- Clarify the child's knowledge and identify the source of concern while discussing the pandemic.

- Provide repeated opportunities for the child to talk about their worries, questions, and feelings about the pandemic and how it affects them. One may not always need to have an answer, but active listening can go a long way.

- Keep the process as a dialogue rather than a statement.

- Keep the conversation hopeful even when the child knows understands the gravity of the situation.

- Ensure them that the health care providers continue to take measures to combat this situation.

- Communicate the facts and ensure an adult's presence to keep them safe.

- Limit media exposure to prevent overwhelmingly inaccurate information.

\section{School}

School refusal may occur at any time but is most common in children ages 5-7 and 11-14 while transitioning to elementary and middle school, respectively. In non-crisis times, school refusal often begins following a period at home when the child becomes closer to the parent, such as a holiday break, long weekend, brief illness, the death of a pet or relative, or change in schools. These children suffer from a paralyzing fear of leaving the safety of their parents and home. Subsequently, prolonged online schooling in the face of pandemic can potentiate school refusal. Therefore, there is also a need for flexible and preventative school-based interventions to enhance children's understanding of loss and address misconceptions about the death and grief process (61). Schools and teachers must aim to provide information about death, offer an appropriate vocabulary; present diverse cultural perspectives; allow the elaboration of eventual losses and offer help to manage grief, demystify media contents and myths; and reflect upon the elements of funeral rites to integrate spiritual and religious perspective (47).

\section{Health Care Professionals}

Health care professionals working with bereaved children should consider children's views of death in their communications during clinical encounters. They can help children to rework their understandings of death as they progress developmentally. The main tasks for grieving children include understanding the loss associated with the state, expressing emotions and strong reactions, remembering the deceased, and learning the integration of the loss in one's life (62). This approach provides opportunities for growth and the realization of "good grief" in the context of irreversible loss and unavoidable sadness. In addition, clinicians should consider exploring children's understanding and needs as part of the management process. These could include: gathering adequate information about fears and anxieties, providing reassurance to reduce child's guilt and self-blame, empathetic listening and validation of child's feelings, helping them with overwhelming emotions, involving them in decision making, promoting routine activities, assisting parents in modeling their grief behaviors and giving the child opportunities to remember the deceased one or talk about them. Additionally, the clinical approach must incorporate cultural and contextual factors that may limit the spread of contagion (63). Therefore, it is crucial is to incorporate traditional religious practices and cultural beliefs that can significantly contribute to clinical challenges while managing the pandemic (64).

\section{CONCLUSION}

COVID-19 Pandemic would influence death-related fears on childhood development, impacting them for years of their life. A bioecological perspective can help us understand the differences between how children's understanding of death is impacted or influenced by their environments compared to adults. This is crucial to consider, as different children react to and are influenced by their environments differently. Adults must refrain from having a predetermined opinion of how a child must respond to a situation over a given period. Bereaved children and adolescents may not have coping skills needed to manage their grief in constructive ways. Therefore, like all bereaved adults, children need to identify, normalize, and express their responses to the loss in their lives. Naming and validating these responses as distinctive aspects of grief process and providing safe space to express their feelings are essential components of a child's coping with loss and grief. These experiences become overwhelming when children are led to view them that way. Nothing is scarier for a child than their feeling of helplessness and fear of losing a loved one.

\section{DATA AVAILABILITY STATEMENT}

The original contributions presented in the study are included in the article/supplementary material, further inquiries can be directed to the corresponding author/s.

\section{AUTHOR CONTRIBUTIONS}

$\mathrm{AC}$ and SY: review of literature for the work, critical revision of the work for important intellectual content, design of the work, drafting of the manuscript, final approval of the version to be published, and agreement to be accountable for all aspects of the work. WA: drafting the manuscript, final approval of the version to be published, and agreement to be accountable for all aspects of the work. All authors contributed to the article and approved the submitted version.

\section{ACKNOWLEDGMENTS}

The authors would acknowledge Dr. Ayesha Mian, Dr. Zehra Fadoo, Dr. Naureen Mushtaq, Dr. Sadaf Altaf, and Dr. Shahzadi Resham from Aga Khan University. 


\section{REFERENCES}

1. Hillis SD, Unwin HJ, Chen Y, Cluver L, Sherr L, Goldman PS, et al. Global minimum estimates of children affected by COVID-19-associated orphanhood and deaths of caregivers: a modelling study. Lancet. (2021) 398:391-402. doi: 10.2139/ssrn.3782441

2. Fong MW, Gao H, Wong JY, Xiao J, Shiu EY, Ryu S, et al. Nonpharmaceutical measures for pandemic influenza in nonhealthcare settings-social distancing measures. Emerg Infect Dis. (2020) 26:976. doi: 10.3201/eid2605.190995

3. Honigsbaum M. Pandemic. Lancet. (2009) 373:1939. doi: 10.1016/S0140-6736(09)61053-9

4. Singh S, Roy D, Sinha K, Parveen S, Sharma G, Joshi G. Since January 2020 Elsevier has created a COVID-19 resource centre with free information in English and Mandarin on the novel coronavirus COVID-19. The COVID-19 resource centre is hosted on Elsevier Connect, the company's public news and information. Psychiatry Res. (2020) 293:113429. doi: $10.1016 /$ j.psychres.2020.113429

5. Guimarães AC, Mau LB, Maunsell R. COVID-19 in children: considerations for returning to school ${ }^{\star}$. Braz J Otorhinolaryngol. (2020) 86:6678. doi: 10.1016/j.bjorl.2020.09.005

6. Corr CA, Corr DM. Key elements in a framework for helping grieving children and adolescents. Illness Crisis Loss. (1998) 6:142-60. doi: 10.2190/IL6.2.c

7. Kastenbaum R, Costa PT Jr. Psychological perspectives on death. Annu Rev Psychol. (1977) 28:225-49. doi: 10.1146/annurev.ps.28.020177.001301

8. Speece MW, Brent SB. Children's understanding of death: a review of three components of a death concept. Child Dev. (1984) 55:167186. doi: $10.2307 / 1129915$

9. Iverach L, Menzies RG, Menzies RE. Death anxiety and its role in psychopathology: reviewing the status of a transdiagnostic construct. Clin Psychol Rev. (2014) 34:580-93. doi: 10.1016/j.cpr.2014.09.002

10. Han PK, Klein WM, Arora NK. Varieties of uncertainty in health care: a conceptual taxonomy. Med Decis Making. (2011) 31:828-38. doi: 10.1177/0272989X10393976

11. Birrell J, Meares K, Wilkinson A, Freeston M. Toward a definition of intolerance of uncertainty: a review of factor analytical studies of the Intolerance of Uncertainty Scale. Clin Psychol Rev. (2011) 31:1198208. doi: 10.1016/j.cpr.2011.07.009

12. Van den Bulck J, Custers K. Television exposure is related to fear of avian flu, an ecological study across 23 member states of the European Union. Eur $J$ Public Health. (2009) 19:370-4. doi: 10.1093/eurpub/ckp061

13. Wong PT, Reker GT, Gesser G. Death attitude profile-revised: a multidimensional measure of attitudes toward death. Death Anxiety Handb. (1994) 121:121-48. doi: 10.1037/t17237-000

14. Corr CA. Elisabeth Kübler-Ross and the "five stages" model in a sampling of recent textbooks published in 10 countries outside the United States. OMEGA. (2021) 83:33-63. doi: 10.1177/0030222819840476

15. Neimeyer RA, Wittkowski J, Moser RP. Psychological research on death attitudes: an overview and evaluation. Death Stud. (2004) 28:30940. doi: 10.1080/07481180490432324

16. Kuuppelomäki M. Attitudes of cancer patients, their family members and health professionals toward active euthanasia. Eur J Cancer Care. (2000) 9:16-21. doi: 10.1046/j.1365-2354.2000.00184.x

17. Warren SL, Sroufe LA. Developmental issues. In: Ollendick TH, March JS, editors. Phobic and Anxiety Disorders in Children and Adolescents: A Clinician's Guide to Effective Psychosocial and Pharmacological Interventions. New York, NY: Oxford University Press (2004). p. 92-115.

18. Gullone E. The development of normal fear: a century of research. Clin Psychol Rev. (2000) 20:429-51. doi: 10.1016/S0272-7358(99)00034-3

19. Greenberg J. Terror management theory: from genesis to revelations. In: Shaver PR, Mikulincer M, editors. Meaning, Mortality, and Choice: The Social Psychology of Existential Concerns. Washington, DC: American Psychological Association (2012). p. 17-35.

20. Menzies RE, Menzies RG. Death anxiety in the time of COVID-19: theoretical explanations and clinical implications. Cogn Behav Ther. (2020) 13:e19. doi: 10.1017/S1754470X20000215

21. Evers NF, Greenfield PM, Evers GW. COVID-19 shifts mortality salience, activities, and values in the United States: big data analysis of online adaptation. Hum Behav Emerg Technol. (2021) 3:107-26. doi: 10.1002/hbe2.251

22. Wheeler L. Toward a theory of behavioral contagion. Psychol Rev. (1966) 73:179. doi: 10.1037/h0023023

23. Bronfenbrenner U. Contexts of child rearing: problems and prospects. Am Psychol. (1979) 34:844. doi: 10.1037/0003-066X.34.10.844

24. Olabi B, Bagaria J, Bhopal SS, Curry GD, Villarroel N, Bhopal R. Population perspective comparing COVID-19 to all and common causes of death during the first wave of the pandemic in seven European countries. Public Health Pract. (2021) 2:100077. doi: 10.1016/j.puhip.2021.100077

25. Kidman R, Margolis R, Smith-Greenaway E, Verdery AM. Estimates and projections of COVID-19 and parental death in the US. JAMA Pediatr. (2021) 175:745-6. doi: 10.1001/jamapediatrics.2021.0161

26. Bergman AS, Axberg U, Hanson E. When a parent dies-a systematic review of the effects of support programs for parentally bereaved children and their caregivers. BMC Palliat Care. (2017) 16:1-5. doi: 10.1186/s12904-017-0223-y

27. Nicola M, Alsafi Z, Sohrabi C, Kerwan A, Al-Jabir A, Iosifidis C, et al. The socio-economic implications of the coronavirus pandemic (COVID-19): a review. Int J Surg. (2020) 78:185-93. doi: 10.1016/j.ijsu.2020.04.018

28. Thevenon O, Adema W. Combatting COVID-19's Effect on Children. Technical Report. OCDE: Paris (2020). Retrieved from: https://www. researchgate.net/publication/341178136_Combatting_COVID_19_effect_ on_children (accessed August 24, 2020).

29. Spielberger CD. Understanding Stress and Anxiety. London: Harper \& Row (1979)

30. Cloninger CR. Temperament and personality. Curr Opin Neurobiol. (1994) 4:266-73. doi: 10.1016/0959-4388(94)90083-3

31. Fegert JM, Vitiello B, Plener PL, Clemens V. Challenges and burden of the Coronavirus 2019 (COVID-19) pandemic for child and adolescent mental health: a narrative review to highlight clinical and research needs in the acute phase and the long return to normality. Child Adolesc Psychiatry Mental Health. (2020) 14:1. doi: 10.1186/s13034-020-00329-3

32. Herrera-Valdez MA, Cruz-Aponte M, Castillo-Chavez C. Multiple outbreaks for the same pandemic: local transportation and social distancing explain the different "waves" of A-H1Nlpdm cases observed in México during 2009. Math Biosci Eng. (2011) 8:21. doi: 10.3934/mbe.2011.8.21

33. Shultz JM, Cooper JL, Baingana F, Oquendo MA, Espinel Z, Althouse $\mathrm{BM}$, et al. The role of fear-related behaviors in the 2013-2016 West Africa Ebola virus disease outbreak. Curr Psychiatry Rep. (2016) 18:14. doi: 10.1007/s11920-016-0741-y

34. Grof S. The experience of death and dying: psychological, philosophical and spiritual aspects. Maps Bull. (2015) 20:9-13. Retrieved from: https://www. spirituality-studies.org/files/1-2-grof.pdf (accessed August 24, 2021).

35. Yoon S, McClean ST, Chawla N, Kim JK, Koopman J, Rosen CC, et al. Working through an "infodemic": the impact of COVID-19 news consumption on employee uncertainty and work behaviors. J Appl Psychol. (2021) 106:501. doi: 10.1037/apl0000913

36. Hunter-Jones P, Jeffs A, Smith D. Backpacking your way into crisis: an exploratory study into perceived risk and tourist behaviour amongst young people. J Travel Tourism Mark. (2008) 23:237-47. doi: 10.1300/J073v23n0 2_18

37. Victor GS, Ahmed S. The importance of culture in managing mental health response to pandemics. In: Huremović D, editors. Psychiatry of Pandemics. Cham: Springer (2019). p. 55-64

38. Wood MJ, Douglas KM. Conspiracy theory psychology: individual differences, worldviews, and states of mind. In: Uscinski, Joseph E, editors. Conspiracy Theories and the People Who Believe Them. New York, NY: Oxford University Press (2018). p. 245-56.

39. van Prooijen JW, Van Vugt M. Conspiracy theories: evolved functions and psychological mechanisms. Perspect Psychol Sci. (2018) 13:77088. doi: $10.1177 / 1745691618774270$

40. Cardoso ÉA, Silva BC, Santos JH, Lotério LD, Accoroni AG, Santos MA. The effect of suppressing funeral rituals during the COVID19 pandemic on bereaved families. Rev Lat Am Enfermagem. (2020) 28:e3361. doi: 10.1590/1518-8345.4519.3361

41. Johnson N. Britain and the 1918-19 Influenza Pandemic: A Dark Epilogue. London: Routledge (2006). 
42. Ali I. From normal to viral body: death rituals during ordinary and extraordinary COVIDian times in pakistan. Front Sociol. (2021) 5:133. doi: $10.3389 /$ fsoc. 2020.619913

43. Schoch-Spana M. Lessons from the 1918 pandemic influenza: psychosocial consequences of a catastrophic outbreak of disease. In: Ursano RJ, Norwood AE, Fullerton CS, editors. Bioterrorism: Psychological and Public Health Interventions. Cambridge: Cambridge University Press (2004). p. 38-55.

44. Dalton L, Rapa E, Ziebland S, Rochat T, Kelly B, Hanington L, et al. Communication with children and adolescents about the diagnosis of a life-threatening condition in their parent. Lancet. (2019) 393:116476. doi: 10.1016/S0140-6736(18)33202-1

45. Czeisler MÉ, Marynak K, Clarke KE, Salah Z, Shakya I, Thierry JM, et al. Delay or avoidance of medical care because of COVID-19related concerns-United States, June 2020. Morb Mortal Wkly Rep. (2020) 69:1250. doi: 10.15585/mmwr.mm6936a4

46. Anderson D, De Souza J. The importance and meaning of prayer rituals at the end of life. Br J Nurs. (2021) 30:34-9. doi: 10.12968/bjon.2021.30.1.34

47. Testoni I, Zielo A, Schiavo C, Iacona E. The last glance: how aesthetic observation of corpses facilitates detachment in grief work. Illness Crisis Loss. (2020). doi: 10.1177/1054137320933592

48. Demaria F, Vicari S. COVID-19 quarantine: psychological impact and support for children and parents. Ital J Pediatr. (2021) 47:1-4. doi: 10.1186/s13052-021-01005-8

49. Akhtar SE. The Wound of Mortality: Fear, Denial, and Acceptance of Death. New York, NY: Jason Aronson (2010).

50. Kogan I. The Struggle Against Mourning. Lanham: Jason Aronson, Incorporated (2007).

51. Huremović D, editor. Psychiatry of Pandemics: A Mental Health Response to Infection Outbreak. Manhasset: Springer (2019). doi: 10.1007/978-3-030-15346-5

52. Comas-Díaz L, Hall GN, Neville HA. Racial trauma: theory, research, and healing: Introduction to the special issue. Am Psychol. (2019) 74:1. doi: 10.1037/amp0000442

53. Abad C, Fearday A, Safdar N. Adverse effects of isolation in hospitalised patients: a systematic review. J Hosp Infect. (2010) 76:97-102. doi: 10.1016/j.jhin.2010.04.027

54. Vahdani B, Javadi SM, Sabzi Khoshnami M, Arian M. Grief process and the COVID-19 pandemic: wise intervention in vulnerable groups and survivors. Iran J Psychiatry Behav Sci. (2020) 14:e103855. doi: 10.5812/ijpbs.103855

55. Davies R. New understandings of parental grief: literature review. J Adv Nurs. (2004) 46:506-13. doi: 10.1111/j.1365-2648.2004.03024.x

56. Neimeyer RA, Keesee NJ, Fortner BV. Loss and meaning reconstruction: propositions and procedures. In: Malkinson R, Rubin SS, Witztum E, editors.
Traumatic and Nontraumatic Loss and Bereavement: Clinical Theory and Practice. Madison Connecticut: Psychosocial Press (2000). p. 197-230.

57. Pfefferbaum B, Shaw JA. Practice parameter on disaster preparedness. J Am Acad Child \& Adolesc Psychiatry. (2013) 52:1224-38. doi: 10.1016/j.jaac.2013.08.014

58. Griffioen AL. Regaining the "Lost Self": a philosophical analysis of survivor's guilt. In: Gerner A, Gonçalves J, editors. Altered Self and Altered SelfExperience. Norderstedt: Books on Demand (2014). p. 43-57.

59. Robertson $\mathrm{R}$, Kadmos $\mathrm{H}$. Crossing the shadow line: collaborative creative writing about grief. New Writing. (2020) 17:21425. doi: 10.1080/14790726.2019.1586955

60. Feraco AM, Dussel V, Orellana L, Kang TI, Geyer JR, Rosenberg AR, et al. Tumor Talk and Child Well-Being: perceptions of "good" and "bad" news among parents of children with advanced cancer. J Pain Symptom Manage. (2017) 53:833-41. doi: 10.1016/j.jpainsymman.2016.11.013

61. Shatz MA. Teaching thanatology in a foreign country: implications for death educators. Death Stud. (2002) 26:425-30. doi: 10.1080/07481180290086754

62. Doka KJ. Children Mourning, Mourning Children. New York, NY: Taylor \& Francis (2014).

63. Manguvo A, Mafuvadze B. The impact of traditional and religious practices on the spread of Ebola in West Africa: time for a strategic shift. Pan Afr Med J. (2015) 22(Suppl. 1):9. doi: 10.11604/pamj.supp.2015.22.1.6190

64. Khaitsa ML, Kaneene JB, Lumutenga NW, Sengendo M. The intersectionality of sociology and health: case studies of the effect of culture on disease. Pan Afr Med J. (2017) 27:13. doi: 10.11604/pamj.supp.2017.27.4. 12446

Conflict of Interest: The authors declare that the research was conducted in the absence of any commercial or financial relationships that could be construed as a potential conflict of interest.

Publisher's Note: All claims expressed in this article are solely those of the authors and do not necessarily represent those of their affiliated organizations, or those of the publisher, the editors and the reviewers. Any product that may be evaluated in this article, or claim that may be made by its manufacturer, is not guaranteed or endorsed by the publisher.

Copyright (C) 2021 Chachar, Younus and Ali. This is an open-access article distributed under the terms of the Creative Commons Attribution License (CC BY). The use, distribution or reproduction in other forums is permitted, provided the original author(s) and the copyright owner(s) are credited and that the original publication in this journal is cited, in accordance with accepted academic practice. No use, distribution or reproduction is permitted which does not comply with these terms. 